\title{
Avangard Sanat Siyasetsiz Düşünülebilir mi?
}

\author{
Mehmet Fatih Uslu*
}

Yirminci yüzyılın ilk yarısı, özellikle edebiyat ve resimde, biçim açısından köktenci yenilikler talep eden farklı sanat gruplarının varlığına tanıklık etti. Bu yenilikçi talepler, kaynağını sadece sanat içi bir biçim tartışmasından değil, geleneğe ve hâlihazırdaki modern yaşama derin bir tepkiden de alıyor ve dolayısıyla savunulan sanatsal yargılar, siyasi bir gizil güç taşıyordu. Gelecekçi (fütürist), dadaist, gerçeküstücü (sürrealist) ve başka sanatsal hareketler, bu biri gerçek diğeri gizil olan çift taraflı talepleriyle "avangard"ı oluşturdular.

Avangard sanat hakkında en önemli iki kuramsal eseri yazmış olan Renato Poggioli ve Peter Bürger, avangardın ortaya çıkışının hangi tarihlere rastladığı ve hangi sanat hareketlerinin avangard sayılacağı konusunda farklı düşüncelere sahip olsalar da avangardı siyasi ve estetik alanların kesişiminde tanımlamaktadırlar. Ann Gibson'un (2002) deyişiyle ikisi de "devrimci sosyopolitik eğilimlerle, sanatsal amaçların çakışmasını" adlandırmak isterken bu terime başvurmuşlardır (s.158). Bu yazıda, avangardın söz konusu çift kutuplu var oluşu, Bürger ve Poggioli'nin metinleri merkeze alınarak kuramsal ve edebiyat merkezli bir bakış açısıyla tartışılacak. Bu tartışmanın sonunda avangard sanat ya da edebiyat için neden salt metin merkezli bir çözümlemenin yetmeyeceği gösterilmeye çalışılacak.

Avangard sanat hakkındaki bir tartışmaya girmeden önce altı çizilmesi gereken iki nokta var. Bunlardan ilki, avangardın bir üst başlık olduğu ve ortak bir sanatsal yöntem, biçim veya üslup önerisini taşımadığıdır. Renato Poggioli'nin (1968) belirttiği gibi, avangardı oluşturan "ideolojik ve psikolojik nitelikler" tek bir paydaya indirgenemeyecek derecede kaotik bir yapıya ve tek bir estetik kategori dahilinde incelenemeyecek bir çeşitliliğe sahiptirler (s. 5). Onları ortaklaştıran, kendilerinden önceki sanatı değer-

* Yrd. Doç. Dr., İstanbul Şehir Üniversitesi Türk Dili ve Edebiyatı Bölümü Illetişim: mfatihuslu@sehir.edu.tr, İstanbul Şehir Üniversitesi, Kuşbakışı Caddesi No: 27, Altunizade, Üsküdar, İstanbul. 
lendirme şekilleri, köktenci estetik ve köktenci siyaseti aynı programın parçaları olarak düşünmeleri ve buradan çıkarak köktenci önerileri olan bir sanat oluşturmalarıdır. Onları aynı kavram altında birleştiren, daha çok reddettikleridir. Matei Calinescu'nun (1987) deyişiyle, "avangard bir üslubu ya da diğerini tercih ettiğini ilan etmez, o zaten kendisi bir üslup içindedir ya da doğrusu bir anti-üslup içinde" (s. 119). Dolayısıyla bu yazıda avangarda bakarken öne çıkacak olan, avangard grupların kendilerinin tek tek sunduğu yöntem, biçim ve üslup önerileri olmayacaktır. Ağırlıkla, bu grupların, kendilerinden öncekilerin söz konusu kategoriler bağlamında ortaya koydukları savlara ve uygulamalara nasıl bir eleştiri yönelttiği ve bu eleştirinin siyasi imaları tartışılacaktır.

İkinci nokta ise avangardın herhangi bir sanatsal ürüne uygulanabilecek kuramsal ya da kılgısal bir üretim ya da tüketim (yazma ya da okuma) yöntemi önerisi olmaktan çok, tarihsel bir olay olarak değerlendirilmesi gereğidir. Buna göre, sanatta her köktenci biçim denemesi veya önerisi avangarda dâhil edilemez; çünkü avangardı belli tarihsel koşullar sınırlandıır. Bugün gelecekçi ya da dadaist biçimleri benimsemek avangard olmak değildir. Özellikle Bürger (2003), avangardın, ancak belli bir tarihsellik içinde kuramsallaştırılabileceği noktasında ısrarcıdır. II. Dünya Savaşı ertesi, avangard benzeri estetik üretim denemelerinin, eleştirel özünü kaybettiğinden avangard sanata dâhil edilemeyeceğini düşünür (s. 116-17).

\section{Avangardın Sözcük Anlamının Gelişimi}

Fransızca bir sözcük olan "avant-garde" köken itibariyle askeri terminolojiye aittir ve "öncü birlik" anlamındadır. Matei Calinescu'nun (1987) belirttiğine göre, kavramın askeri anlamı dışında edebî sahada ilk kullanılışı, 16. yüzyıl Fransa'sına uzanacak kadar eskidir (s. 98). Fakat kavram, kültürel ve siyasi alanda etkin bir kullanıma ancak 19. yüzyılda kavuşmuştur. Donald D. Egbert (1967), bu ilk kullanımın Fransız Devrimi sonrası St. Simon ve öğrencileri arasında geliştiğini belirtmektedir. St. Simon, bir tür sosyalist toplum fikri üzerinde düşünürken sanatın bu toplumda nasıl bir işlev göreceğini sorgulamıştır. Buna göre sanat, toplumsal açıdan faydalı olmalı ve sanatçı da sosyalist toplumun gerçekleştirilebilmesi için "avangard", yani "öncü" rolünü benimsemelidir (s. 343). Böylece avangard, bir kültürel nosyon olarak ilk tanımlanışında bir siyasi içeriğin içinde şekillenir. Bu içeriğin gelişimini takip ederek sanatçının köktenci, militan ve partinin hizmetinde bir gönüllü olması çağrısında bulunulan Stalin dönemi Sovyet Rusya'sına dek gelinebilir.

Doğrudan köktenci bir estetiğe göndermede bulunan "avangard sanat" kavramının ilk kullanımı ise Poggioli'nin (1968) belirttiğine göre, Neo-Latin dillere ve kültürlere ait olmalıdır. Buna göre İspanyol ve İspanyol-Amerikan kültürlerinde bu sözce sıklıkla kullanılmıştır. Zaten avangard sanatı bütünlüğü içinde ilk kavramaya çalışan da yine bir İspanyol, Ortega y Gasset'dir (s. 5). Yine Poggioli'nin yazdığına göre sözce, Fransa 
ve İtalya'da daha derin köklere sahip olmuş ve daha yaygın tartışılmıştır. Rusya'da ise Ekim Devrimi sonrasında milliyetçi sosyalizm kuvvetlenene kadar etkin ve kullanılan bir kavramdır (s. 6-7).

İşte tam bu noktada, yani siyasi köktencilikle estetik köktenciliğin buluştuğu yerde, bu yazının esas tartışma konusu ortaya çıkmaktadır. Zira bu buluşma noktasında gerçek avangard doğar.

\section{Avangardın Tarihsel Oluşumu ve Kavramsal Çerçevesi}

19. yüzyıl, toplumsal hayatın her alanında alt üst oluşlara tanıklık etti. Sanayi Devrimi ertesinde modern kapitalizm, kırsal geçim kalıplarını ortadan kaldıran ve böylelikle köylü nüfusu kente taşıyan, iktidarı toprak sahibinden sanayiciye aktaran dinamikleriyle yaşamı tüm boyutlarıyla değiştirdi. Kentlerde, önce çeşitli sınıfların ve aynı zamanda bu sınıfların yan yana görüldüğü bir kamusal alanın oluşumu, teknolojik gelişmenin gündelik yaşama nüfuz etmesi, ulaşım ve haberleşme alanındaki devasa değişim hem toplumsal ilişkilerin dokusunu hem de gündelik pratiklerin deneyimlenme biçimini büyük ölçüde dönüştürdü. Marx ve Engels'e göre, çağın öznesi olan burjuvazi, insanlığı feodal zincirlerinden kurtarsa da "kişisel değerin değişim değerine dönüştüğü, sayısız kazanılmış özgürlüğün yerini tek bir özgürlüğe, serbest ticarete" (Marx ve Engels, s. 38) bıraktığı bir çağ yaratmıştı. Üretim ilişkilerinin bu köklü değiş̧imiyle birey, içinde güven duyduğu dural toplumsal yapılardan kopuyor, bambaşka bir deneyime zorlanıyordu.

Sanatçının bu hızla dönüşen çağa ayak uydurmaya çalışırken ürettiği tepki zaman zaman aşıılıklara kaydı. Kentleşme ve kentleşmenin kamusal ve özel yaşamın eski alışkanlıklarını ortadan kaldırırken ortaya çıkan değişim ve hızın yarattığı korku, sanatın ekseninin bir ucunda dururken diğer uç, eski olan her şeyden iğrenme ve yeniyi coşkuyla karşılama ile tanınıyordu. Avangard sanatçı, bu uçlardan ikincisinde, derin bir teknoloji tutkusu, kitle kültürüne duyulan nefret ve geleneğe karşı öfke ile sadece sanatın değil, hayatın da tüm geçmiş bağlarından koparılarak yeni baştan yaratılması iddiasıyla ortaya çıktı.

Esasında bu duygu ve taleplerin, sadece avangardın ürünü olduğunu söylemek zordur. Romantiklerden Baudelaire'e, ondan 19. yüzyıl başında etkinlikleri zirve noktasına varan simgeci şairlere kadar pek çok sanatçıda ve özellikle de şairlerde bunların benzerlerine rastladığımızı söyleyebiliriz. Avangard, kendinden önceki akımlardan nasıl ayrıştıılabilir? Yazının başında da söylendiği gibi bu, daha çok sanatsal yapıların tarihsel gelişimi ile ilgili olmalıdır. Raymond Williams (1989), avangardın ortaya çıkısını açıklamak için 19. ve 20. yüzyıllarda birbirini izleyen üç evreden söz etmektedir. Buna göre ilk evrede, "sanatta piyasa güçlerinin artan hâkimiyeti ve resmî akademilerin ilgisizliği karşııında kendi bağımsız pratiklerini korumak isteyen yenilikçi gruplar" ortaya 
çıkmıştır. İkinci evrede bu gruplar, "kendi üretim, dağıtım ve tanıtım imkânlarını oluşturma" çabasına girişmişlerdir. Son evrede ise "tamamen muhalif oluşumlara dönüşen bu gruplar, sadece kendi üretimlerini teşvik edecek yapıları kurmakla kalmamış, kültürel yapılardaki düşmanlarına, hatta onların iktidarının kaynağı olan tüm toplumsal düzene karşı saldırıya geçmişlerdir" (s. 50-51). Williams'a göre bu evrelerden ikincisi modernizme, üçüncüsü ise avangarda karşılık gelmektedir.

Avangardı modernizmden ayırmak, avangarda kavramsal bir çerçeve verebilmek adına hayati bir önem taşımaktadır. Zira, avangard hareketlerin estetik talepleri ile modernist sanatınkiler arasındaki benzerlik sıkça dikkat çekilen bir noktadır. Buradan hareketle avangardın, modernizmin bir görünüşünden başka bir şey olmadığı dahi iddia edilebilir. Fakat onu modernizmden ayıran ve bu yazı için hayati olan bir nokta vardır: Avangardın siyasal konumlanışı ve bu konumlanışı sanat içinden gerçekleştirişi; yani Charles Russell'ın deyimiyle avangardın "eylemci estetik"i (aktaran: Man, 1991, s. 8). Bu bağlamda Paul Man'ın (1991) saptaması önemlidir: "Modernizm ile avangard arasındaki ortaklığa ya da benzerliğe odaklanan çalışmalar estetik konuları vurgulamak eğilimindeyken, ikisinin arasındaki farkı tartışmak isteyenler ideolojiyi vurgulamaya teşnedirler" (s. 10). Bu saptama, avangardın salt sanatsal üretiminin onu benzerlerinden ayırmada yeterli olmayacağını göstermektedir.

Avangard kuramının önemli ismi Peter Bürger de avangardı anlamak için Williams gibi tarihsel perspektifli bir kuramsal açıklama önermektedir. Bürger'e (2003) göre sanat, 18. yüzyıldan itibaren sarayın, kilisenin ve piyasanın hâkimiyet iddialarına karşı direnmiş, kendi özerkliğinde ısrarcı olmuş ve bu özerklik iddiasında 19. yüzyılın sonlarında simgecilik ve estetizm ile zafere ulaşmıştır (s. 91-98). Bu son noktada sanat dışarıya kapanmış, toplumsal pratiklerden uzak, kurumsal bir yapı haline gelmiştir. Bürger, "kurumsal olarak sanat" kavramından "sanat içerisindeki üretici ve tüketici aygıtın yanı sıra, sanatla ilgili olarak belli bir zamanda hâkim olan ve eserlerin algılanışını önemli ölçüde belirleyen fikirler"in kastedildiğini belirtmektedir (s. 63). Bu kurumsallaşma ve özerklik, aynı zamanda sanatın toplumsal pratikleri etkileme kabiliyetini kaybettiğini ima etmektedir. Toplumsaldan uzaklaşmak, sanatı iyice kendine döndürür. Ali Artun'un (2003) ifadesiyle, "hayattan olabildiğince yalıtılması sonucu, sanatın içeriği, kendi formuna dönüş[müştür]. Başka deyişle içeriği biçimi ol[muştur]" (s. 21). Bürger (2003), bu durumu, avangard hareketlerin doğuşu için milat olarak belirler:

Sanat, kendisine yabancı her şeyi dışında bıraktığında, kendi açısından ister istemez sorunlu hale gelir. Kurum ile içeriklerin örtüşmesiyle birlikte, burjuva toplumunda sanatın özünün toplumsal etkisizlik olduğu açığa çıkar; bu durum da sanatın özeleştirisine davetiye çıkarır. Bu özeleştiriyi gerçekleştirmek, tarihsel avangard hareketlerine düşecektir. (s. 71)

Bürger, "tarihsel avangard hareketleri" derken ilk planda gerçeküstücülük, dadaizm ve Rus gelecekçiliğini kastetmekte ve bazı kısıtlamalarla beraber bu gruba İtalyan gele- 
cekçiliği ve Alman dışavurumculuğunun da katılabileceğini belirtmektedir. Bütün bu hareketler, aralarındaki farklara rağmen, sanatsal geleneğe karşı köktenci bir karşı çıkışta ortaklaşırlar: "Bu hareketlerin ortaklığı, aralarında yer yer muazzam farklar olmasına rağmen, daha önceki sanatın tekil prosedürlerini değil, o sanatı toptan reddetmeleri, böylece gelenekten radikal bir kopuş gerçekleştirmeleridir. En uç örneklerinde, başat hedefleri burjuva toplumunda geliştiği şekliyle sanat kurumudur" (s. 55).

Böylelikle avangard, sanat kurumunu ortadan kaldırarak sanatı tekrar topluma hediye etmek, onu hayat pratiğine tekrar kazandırmak amacıyla yola çıkar. Fakat bu, hayata "yamanmış" bir sanat olmayacaktır. "Avangardistlerin farkı, temelini sanatta bulan yeni bir hayat pratiği örgütleme çabalarıdır" (Bürger, 2003, s. 105). Bu sanat, yaşanan hayatı da, tıpkı hâlihazırdaki sanatsal araçları kökten reddettiği gibi, dışarıda bırakmaktadır: "Ancak eserlerinin içerikleri mevcut toplumun (kötü) hayat pratiğinden tamamen ayrı olabilen bir sanat, yeni bir hayat pratiğinin örgütlenmesine götürecek bir başlangıç noktası olacaktır" (s. 105). Böylelikle, bu tarihsel perspektifle, radikal bir estetik, radikal bir siyasi pratiğin özü haline dönüşme şansı bulur. Bürger'e göre tarihsel avangard, bu radikal pratiği, sadece iki dünya savaşı arasında sürdürebilmiş, yazının başında da belirtildiği gibi, sonra düzen tarafından kendi içine çekilmiş, eleştirel kimliğini kaybetmiştir.

Avangardın diğer önemli kuramcısı Poggioli içinse avangard daha erken başlamış ve en has ifadesini 1880 'li yıllarda bulmuştur. Hatta iki dünya savaşı arasında oluşan ve bu yazıda avangard kabul ettiğimiz hareketler onun için avangard olmanın ölçütlerini tam olarak yerine getirmemektedir. Poggioli'nin bu sonuca varmasında en önemli etken, iki dünya savaşı arasındaki avangard hareketlerde, köktenci bir muhalif siyaset önerisi değil, aşağıda da gösterileceği gibi birbirine 180 derece zıt yönlere dahi gitmeye eğilimi olan bir anarşizm görmüş olmasıdır. Poggioli (1968) için avangardda önemli olan, Bürger'den farklı olarak, estetik taleplerin tetiklediği bir siyasi yönelimden çok, estetik köktencilikle siyasi köktenciliğin birinin diğerinin sonucu olmadan beraberce var olmasıdır (s. 11).

Poggioli bu yazıda, avangard kabul edilen hareketleri, eylemcilik (activism), düşmanca uzlaşmazlık (antagonism), hiççilik (nihilism) ve kendini feda etme (agonism) özelliklerinin belirlediğini iddia etmektedir (s. 24-26). Bu özellikler, belli bir plan program dâhilinde olmayan, sebebi ve amacı değişken, uçlara gitmeye teşne bir eylem tutkusunun varlığına işaret ederler. Bunun uygulayıcısı olan sanatçılar ise ancak toplumsal olana yabancılaşmış, kendini kapatmış bir seçkinler topluluğu olabilir (s. 31 ve 89-94). Poggioli, bu noktada, Ortega y Gasset'in fikirlerine yaklaşmaktadır. Konu hakkındaki öncü yorumlardan birini yapan (1925 yılında) Gasset'e (1998) göre, bu yeni sanatın niteliklerini belirlemek çok zor olsa da, onun insanı dışlayan (s. 158), kitleyi dışarıda bırakan ve ancak azınlığın anladığı bir üretim olduğu saptanabilir (s. 150). Böyle bir tabloda Poggioli'ye (1968) göre, bu hareketlerin ürettiği siyaset önerileri, anarşist bir zihniyetin ürünleridir ve asla programlı bir siyasetle bütünleşemez: "Bir başka deyişle, 
sanatsal devrimin, toplumsal devrim ile özdeşleşmesi, şimdi saf retorikten, içi boş ağızlara pelesenk olmuş bir sözden daha fazla bir anlama sahip değildir" (s. 96).

Bu noktada, Bürger ve Williams'ın bir uçta, Poggioli ve Gasset'in diğer uçta olduğu düşünülmemelidir. Williams'ın hâkim sanat ortamına saldırıya geçen anarşist avangardı da, Bürger'in kendini topluma kapatmış sanat kurumuna saldıran tarihsel avangardı da, avangardın kitle kültürüne övgüyle yaklaştığını ya da muhalif saldırılarının hatları belirli bir siyasi-sanatsal proje etrafında oluştuğunu iddia etmemektedir. Poggioli ve Gasset ise bu saldırıyı anlamsız ve kötücül değil, tarih akışının doğal bir sonucu saymakta (Poggioli, 1968, s. 178), dolayısıyla kendilerini Bürger ve Williams'ın karşısına konumlamamaktırlar. Yine de Bürger'in avangard hareketlere çok daha sempatiyle baktığının açıkça görüldüğünü de belirtmek gerekir.

Bütün bu kuramsallaştırma gayretinin nesnesi olan avangardist tecrübenin edebiyata yansıyan görüntüsüne bakmak, hem tarihsel olanın gözetiminde bu kuramları değerlendirmek hem de buradan edebiyat eleştirisi için ne tür sorular üretebileceğimizi görmek bakımından önemli olabilir.

\section{Avangard Edebiyatın İşaret Ettiği Siyaset}

Williams, Poggioli ve Bürger'in avangardı kavramsallaştırmaları noktasında açık bir soru ortaya çıkıyor: Bu anarşist tabiatlı siyasal talepler edebiyat üretimine nasıl yansıyor? Köktenci siyasal taleplerle, köktenci estetik talepleri aynı programın parçaları olarak algılayan avangardın, bu taleplerini ürün düzleminde nasıl kurguladığını anlamak için avangard hareketlerin edebî üretimlerinin en azından genel yapılarına bakmak gerekiyor.

Hem gelecekçilik hem de gerçeküstücülükte şiir her zaman merkezde olmuştur. Zira şiirsel üretim, avangard hareketlerin beklentilerini karşılamaya en uygun türdür. Tarihsel ortaya çıkış sıralarına uyarak yazarsak hem gelecekçilik, hem dadacılık hem de gerçeküstücülük, kendilerinden önce var olan sanatsal pratikleri "düşmanca bir uzlaşmazlık"la reddetmekle kalmamış; yeni bir sanatın, akıldışının sesini geri getiren, bunun için çağrışımın tüm kontrollerden uzak tutan bir yaklaşım benimsemesi gerektiğini iddia etmişlerdir. Bu noktada, "ben"i imha etmek, sanat üreticisini özneliğini ortadan kaldırmak, Octavio Paz'ın sözleriyle "sanatçının sesini artık yalnız onun sesi olmaktan çıkarıp herkesin sesi" kılmak (aktaran Avcı, 2004, s. 3), başta gerçeküstücüler olmak üzere tüm avangardistlerin hedefidir. Tristan Tzara'nın şiir için verdiği ünlü "reçete", sanatçının öznelliğine yönelik bu bilinçli saldırıyı apaçık ortaya koyar:

Bir gazete alın. Bir makas alın. Gazeteden, şiirinizin ne kadar uzun olmasını istiyorsanız, o uzunluğa yakın boyutta bir makale seçin. Makaleyi kesip çıkarın. 
Sonra da dikkatli bir şekilde makaledeki sözcükleri teker teker kesip çıkarın ve bunları bir torbaya koyun. Torbayı hafif hafif sallayın. Sonra birbirinin ardısıra sözcükleri torbadan çekin. Sözcükleri çekiliş sırasına uyarak bir kâğıt üzerine özenle kopye edin. Oluşan şiir size benzeyecektir. Ve işte siz, sınırsız özgünlüğün ve tatlı duyarlıı̆ın yazarı. (akt: Lewis, 1990, s. 5)

Gerçeküstücülük, Dada'nın esinlediği bu bakış altında şiirini, Yvonne Duplessis'in (1991) de belirttiği gibi mizahın, düşün, çılgınlığın ortasında kurar (s. 24-41). Şiirin, tüm bireysel ve toplumsal bağlarından kurtarılması gibi bir ütopik amaçtan "otomatik yazma" gibi yine Duplessis'in sözleriyle "insanı olduğu gibi ilkel doğası içinde gösterebilmek, onda uygarlıktan kazanılmış ne varsa atmak" (s. 45) işlevi yüklenen teknikler üretir. Octavio Paz'ın (2004) deyimiyle "gevşemenin en üst düzeyinde" (s. 15) bir faaliyet olan otomatik yazma ile Andre Breton'un sözleriyle "insanın sözüne başlangıçtaki arılığını ve yaratıcı gücünü yeniden kazandırmak" (s. 15) hedeflenir. Bu hedeflenen kurulum kaynağını ise yine Breton'un anlattığı şu anekdot özetlemektedir: Breton'un arkadaşlarından Saint-Paul Roux, her gece yatmadan önce kapısının üstüne, üzerinde "Şair Çalışıyor" yazan bir levha asmaktadır (Duplessis, 1991, s. 52).

Aralarında birçok fark olsa da gelecekçilik de şiiri, geçmişi tamamen reddeden yeni bir alanda kurmak kaygısındadır. İtalyan gelecekçilerin lideri Marinetti, "edebiyatta 'ben'i yok etmenin" (aktaran: Lawton, 1976, s. 415) esas olduğunu ilan etmektedir. O da tıpkı Rus gelecekçisi Krucenik gibi, kendilerinden önceki simgeci şiirin içeriğinden duyulan tiksintinin de etkisiyle, insan psikolojisini reddetmekte, şiirin akı ötesi bir dille yazılması gerektiğini iddia etmektedir (Lawton, 1976, s. 416). Bu düşünceler, gelecekçileri figüratif, uydurma sözcüklerle ve sözcük oyunlarıyla dolu, gürültücü bir şiire götürmüştür. Rus gelecekçileri, İtalyan muadillerinden bu noktada daha köktenci olmakla birlikte, John J. White'ın (1990) deyimiyle gelecekçilik, bir tür "dilbilimsel edebiyat" kurmuştur (s. 215-18).

Bu bilgilerden sonra, avangard için siyasetin ne kadar önemli olduğu daha da açık ortaya çıkmaktadır. Gasset'in (1998) de belirttiği gibi karşı karşıya olduğumuz, "sanatçının kendisi[nin] sanatını önemsiz gördüğü" (s. 175) bir çağdır. Avangard sanatçılar da bu durumun bilincindedir. Örneğin gerçeküstücülerin önderi Breton, Selahattin Hilav'ın (2003) belirttiği gibi, kendini şair saymamakta, edebiyatın sonunun geldiğini sık sık tekrarlamaktadır (s. 14-15). Sanatın bu önemsizliği ve şiirin bilinçaltına bırakılması, şiirin herkesin ortak dili haline getirilebilmesi gibi amaçlarla el ele gitmektedir. 1920'lerde, tarihsel gelişimin ve grupların iç dinamiklerin sonucu olarak gerek gelecekçilik, gerekse gerçeküstücülük—dadacılık tarihin sayfalarına karışmıştır artık—siyasi kaygılarla daha sıkı yüzleşmek zorunda kalmışlardır. Hilav'ın sözleriyle "gerçeküstücülük, kendini bir sanat akımı olarak değil, bir devrim hareketi olarak" (s. 9) görmekte; Paz'a (2004) göreyse "yeni bir sanat değil, yeni bir insan yaratmak" (s. 16) peşinde koşmaktadır. Rus gelecekçiler ise herkesin edebiyatçı, edebiyatçının zanaatkâr olduğu; edebiyatın hayata sindiği bir edebiyatın peşindedir artık (Barooshian, 1971, s. 38-46). 
Öte yandan, Poggioli'nin altını çizdiği avangardı belirleyen dört eğilimin, tüm bu çaba içinde hiçbir zaman hâkimiyetini kaybetmediğinin altı çizilmelidir. İtalyan gelecekçiliğin, faşizmin önde gelen savunucularından birine dönüşmesi, avangard sanatın kararsız özü hakkında fikir vericidir. Fakat bu kararsızlığın karartamadığı çok önemli bir nokta vardır: Avangard, sanatın kutsandığı, yüceltildiği bir çağın sadece sanatını değil, tüm ürünlerini ve pratiklerini reddetmek niyetindedir. Bu niyet, genelde sanatı, özelde edebiyatı yeni bir hayat tahayyülünün içinde tekrar düşünmemizi sağlar.

\section{Sonuç}

Marksçı düşünüşün iki önemli ismi, Benjamin ve Lukacs avangardın gelişimine hem bizzat tanıklık ettiler hem de sanatın siyasi dolayımı üzerine düşünen kişiler olarak avangard üzerinden gelişen tartışmalara etkin bir şekilde katıldılar. Brecht'le giriştikleri ünlü dışavurumculuk tartışmasında Lukacs, avangard akımlarındaki irrasyonalizmi açıkça faşizmle aynı kefeye koydu ve ağır bir çürümenin simgesi olarak gördü (Gluck, 1986, s. 850). Benjamin içinse yeni bir devlet ve yeni bir hayat için tamamen yeni metinlere ve yeni okuma biçimlerine ihtiyaç vardı ve avangard metinler, bu çaba için uygun alanlar açıyordu (Jennings, 2004, s. 32-33). Zaten sanat ürününün biricikliğini kaybettiği bu çağda, artık ufukta görünen ve umut veren sanatın siyasetleştirilebilmesi imkânı idi (Benjamin, 2004, s. 79). Dadacılık örneğini veren Benjamin, Bürger'e ilham verici bir şekilde Dadacılığın sanatsal ürünün biricikliğinin yitirilmesiyle nasıl başa çıktığından övgüyle bahsetti (s. 74).

Sonuçta tüm bu önemli düşünürlerin ve avangard hakkındaki geniş bir literatürü kapsayan çalışmaların ağırlıkla bir noktayı tartışmak durumunda kaldıklarını görüyoruz: politik sanat. Avangard sanat, siyaset ile sanatın karşılıklı ilişkisini incelemek adına zengin bir alan konumunda görülüyor. Zira, köktenci sanat içi taleplerin köktenci siyasi mücadelelerle bu şekilde içe geçmesi; sanatsal kaygıların siyasetten ne kadar bağımsız olabileceği ile olmasının ne kadar gerekli olduğunu sorgulamak ve sanatçının toplumsal işlevi ile sanatsal ürünün toplumsal eleştiri kabiliyetini tartışmak adına verimli bir deneyim alanı sunuyor.

\section{Kaynakça}

Artun, A. (2003). Kuramda avangardlar ve Bürger'in avangard kuramı. Peter Bürger içinde. Avangard kuramı (s. 9-32). (E. Özbek, çev.). İstanbul: İletişim Yayınları.

Avcı, A. (2004). Bir büyük reddiye ya da hakiki bir hayatı yaşamak. Varlık, 1167, 3-8.

Barooshian, V. D. (1971) Russian Futurism in the late 1920's: Literature of Fact". The Slavic and East European Journal 15 (1), 38-46.

Benjamin, W. (2004) Tekniğin olanaklarıyla yeniden üretilebildiği çağda sanat yapıtı. Pasajlar içinde (s. 50-86). (A. Cemal, çev.). İstanbul: Yapı Kredi Yayınları. 
Bürger, P. (2003). Avangard kuramı. (E. Özbek, çev.). İstanbul: Illetişim Yayınları.

Calinescu, M. (1987). Five faces of modernity. Durham: Duke University Press.

Duplessis, Y. (1991) Gerçeküstücülük. (ì. Yerguz ve E. Çamurdan, çev.). İstanbul: İletişim Yayınları.

Egbert, D. D. (1967). The idea of 'Avant-Garde' in art and politics. The American Historical Review, 73 (2), 339-66.

Gibson, A. (1992). Avant-Garde. In R. S. Nelson \& R. Shiff (Eds.), Critical terms for art history (ss. 201-216 ). Londra: University of Chicago Press.

Gluck, M. (1986). Toward a historical definition of modernism: Georg Lukacs and the avant-garde". The Journal of Modern History, 55 (4), 845-82.

Hilav, S. (2003). Edebiyat yazıları. İstanbul: Yapı Kredi Yayınları.

Jennings, M. (2004). Walter Benjamin and the European avant-garde. In D. S. Ferris (der.) Cambridge companion to Walter Benjamin (pp. 18-34). New York: Cambridge University Press.

Lawton, A. (1976). Russian and Italian Futurist Manifestoes. The Slavic and East European Journal, 20 (4), 405-420.

Lewis, H. (1990). Dada turns red: The politics of Surrealism. Edinburgh: Edinburgh University Press.

Man, P. (1991). The theory death of the avant-garde. Bloomington: Indiana University Press.

Marx, K., \& Engels, F. (1971). Manifesto of Communist Party. Boston: Allen and Unwin.

Ortega y Gasset, J. (1998). Sanatın insanı dışlaması. Tarihsel bunalım ve insan içinde. (çev. yay. haz. N.G. Işık, s. 146-179). İstanbul: Metis Yayınları.

Paz, O. (2004). Gerçeküstücülük. (A. Cemal, çev.). Varlık, 1167, 12-19.

Poggioli, R. (1968) The theory of the avant-garde. (G. Fitzgerald, çev.). Cambridge: The Belknap Press of Harvard University Press.

Williams, R. (1989). The politics of modernism. Londra: Verso.

White, J. J. (1990). Literary Futurism. Oxford: Clarendon Press. 
